\title{
Realismo musical, nacionalismo e a Série Brasileira de Nepomuceno
}

\author{
Norton Dudeque ${ }^{1}$ \\ (Universidade Federal do Paraná)
}

\begin{abstract}
Resumo
O texto aborda a utilização de elementos estruturais na música que podem ser relacionados a Realismo em música. A Série Brasileira de Nepomuceno é frequentemente classificada como uma das obras precursoras do nacionalismo na música brasileira. No entanto, outras vertentes de entendimento da obra podem ser consideradas. Neste texto, Realismo em música é abordado com o propósito de prover uma alternativa no entendimento da narrativa musical nesta obra de Nepomuceno. Realismo em música; nacionalismo; Nepomuceno; Série Brasileira.
\end{abstract}

Palavras-chave: Realismo em música; nacionalismo; Nepomuceno; Série Brasileira.

\footnotetext{
${ }^{1}$ Norton Dudeque é professor do Departamento de Música e Artes Visuais da UFPR e tem atuado na área de teoria e análise musical. Seus trabalhos abrangem a teoria musical de Arnold Schoenberg e estudos analíticos e musicológicos da música brasileira do séc. XIX e XX.
} 
I.

Definições de Realismo musical ou a respeito da representação de Realismo em música são escassas. Notável neste sentido, é a falta de um verbete dedicado ao assunto em até mesmo publicações de referência como New Grove Dictionary of Music and Musicians e Die Musik in Geschichte und Gegenwart. No primeiro, o leitor que for ali procurar será instruído a procurar o verbete Verismo, no segundo inclui-se uma breve discussão no verbete Absolute Musik. Na contramão desta tendência, Dahlhaus escreveu em 1982 sua monografia dedicada ao assunto: Musikalischer Realismus: Zur Musikgeschichte des 19. Jahrhunderts, traduzido para o inglês como Realism in Nineteenth-Century Music (1985). No seu texto, Dahlhaus não alcança uma definição sobre o termo, mas levanta uma série de questões pertinentes que serão abordadas neste texto. Na música brasileira, a Série Brasileira de Alberto Nepomuceno tem sido classificada como precursora do nacionalismo, no entanto, esta obra pode ser considerada como ilustrativa de tendências estéticas provindas do pensamento europeu, que adotadas na literatura e na estética brasileira, engendraram uma obra ilustrativa do Realismo em música. Neste texto, Realismo em música é ilustrado em uma análise da Série Brasileira de Alberto Nepomuceno e tem como objetivo de prover uma alternativa no entendimento desta obra tão capital para a música brasileira.

Uma das primeiras tentativas de definição sobre Realismo em música no século XX é elaborada por Norman Cazden, que define Realismo em música como sendo "a totalidade de referências concretas às experiências comuns dos seres humanos como incorporadas em todos os elementos formais da arte musical" (Cazden, 1951, p. 150). Dahlhaus aponta para a dificuldade desta definição argumentando que Cazden iguala a importância do conteúdo musical com os elementos de Realismo. De fato, Cazden propõe distinções importantes no seu texto entre "realismo", "naturalismo", "pictorialismo", mas ao igualar Realismo ao conteúdo da música, todas sua distinções se esvaem. Assim, ele entende Realismo de uma forma abstrata onde os elementos musicais mais diversos podem expressar experiências próprias da realidade humana. Em 1955 Cazden tentou explicar seu entendimento de Realismo musical aplicado à música abstrata 
utilizando como exemplo a Sonata K. 545 de Mozart. A sua argumentação é centrada em associações de tipos de música onde Realismo é mais facilmente identificável. Assim, na Sonata de Mozart, Cazden associa o primeiro movimento a uma cena dramática, o segundo a uma ária e o terceiro a uma dança. Ao final ele afirma que Realismo em música "consiste na referência de imagens musicais ao mundo humano onde estas imagens são criadas. A imagem é ao mesmo tempo forma [musical] e significado, forma e substância, meio e objeto" (Cazden, 1955, p. 38).

A classificação costumeira da música do século XIX, das primeiras décadas às últimas, como Romântica, por vezes parece ser equivocada. Na história da literatura e das artes visuais observa-se, na segunda metade do século XIX, uma tendência a ser classificada como a época do Realismo, ou no mínimo dominada pelos ideais realistas. O que nos leva a questionar a classificação homogênea do Romantismo musical. No entanto, Dahlhaus aborda a impossibilidade de associação entre o Realismo predominante na literatura e as artes visuais (germânicas) do século XIX com o romantismo musical. De fato, o que ele chama de postulado materialista e sua forma oposta, a idealista, têm uma suposição em 138 comum: "a noção de que todas as coisas ou eventos contemporâneos possuem uma unidade de substância, ou no mínimo um Zeitgeist comum, contra o qual a não-contemporaneidade pode ser medida" (Dahlhaus, 1983, p. 125). Ademais, a própria noção de uma arte romântica originada na era realista contradiz a ideia de um Zeitgeist comum (Dahlhaus, 1985, p. 12).

É neste sentido a distinção que Geck (2001, p. 94-102) propõe entre discursos de Realismo na literatura e na música. Muito embora o termo tenha sido utilizado por críticos alemães em relação à literatura germânica, na música ele foi primeiramente utilizado em relação à música germânica pelo musicólogo belga François-Joseph Fétis. Uma das primeiras referências ao Realismo em música aparece em uma série de artigos de Fétis em 1853, onde ele emprega o termo "réalité". ${ }^{2}$ O termo, neste caso, é associado à imitação da natureza e ao conceito estético onde a "verdade" sobrepuja a "beleza". Ademais, Fétis também parece

${ }^{2}$ Fétis apresentou estas ideias na Revue et Gazette musicale 20, n. 18 (11 de julho de 1852. p. 227); e 20, n. 47 (20 de novembro de 1853, p. 403-404). 
atribuir uma importância ao conceito como um "movimento político", uma consequência artística do movimento social e político francês de $1848 .^{3}$ Além da politização do termo, outros dois aspectos se tornam importantes: o primeiro diz respeito à associação entre realismo e a música do futuro representada pela música de Wagner; o segundo, implícito, indica uma confusão no objeto da crítica propriamente dita (vide Garratt, 2003, p. 460-462). Mas depreende-se que o termo Realismo, como entendido por Geck, adquire uma conotação sócio-política, mesmo quando aplicado à música. Ademais, Geck também aborda este assunto enfatizando que, depois de 1830, o termo era usado em textos sobre estética na Alemanha, com uma conotação de imitação da natureza em contraste ao idealismo artístico. Por fim, a partir de 1850, o termo também passa a conotar um programa artístico.

Dahlhaus, por sua vez, descreve uma evolução da questão de imitatio naturae como uma das premissas da arte nos séculos XVII e XVIII até seu entendimento no século XIX. Em particular, ele lista características para a música do século XVII: 1. A imitação de sons não musicais; 2. Fenômenos acústicos que podem representar movimento espacial e temporal; 3. Imitação de inflexões da fala, representando tanto uma imitação da natureza quanto uma imitação relacionada à emoção, e que nos remete à retórica musical do barroco. Estas poucas características listadas, referem-se a uma ideia de natureza fixa, estática, ou seja, natura naturata. A partir do século XVIII, esta ideia é reinterpretada como natureza criativa, ou natura naturans. Entre as características que Dahlhaus lista, encontram-se: 1. Tonmalerei, "pintura musical", que passou a ser vista como autenticamente subjetiva e expressando sentimentos na música (o exemplo que Dahlhaus cita é a Sinfonia Pastoral de Beethoven); 2. Os movimentos espacial e temporal passam a ser entendidos como metáforas possíveis; 3. Inflexões da fala são reinterpretadas para a realização da expressividade musical, como proposta

\footnotetext{
${ }^{3} \mathrm{Em} 23$ de fevereiro de 1848 a monarquia representada pela dinastia Orleans foi deposta e a Segunda República declarada. Em 23 de junho do mesmo ano foram levantadas barricadas no leste de Paris e trabalhadores combateram as autoridades contra 0 fechamento de instituições de caridade. Além disso, eclodiram revoluções na Europa central e oriental em função de regimes governamentais autocráticos e de crises econômicas. Surge também um movimento nacionalista engendrado pelas minorias da Europa central e oriental e a destituição de monarquias europeias.
} 
por C. P. E. Bach, que origina a emoção. Ao final do século XIX estas concepções mudam novamente, assim Dahlhaus lista: 1. Tonmalerei passa a ser sempre designada como "realista" ou "naturalista". Muito embora a visão conservadora adotasse uma postura negativa em relação ao Realismo, Tonmalerei foi visto como polêmico, uma rebelião contra a estética do "belo na música"; 2. A proclamação da "objetividade" como uma forte reação à estética do Gênio que dominou a era do romantismo; 3. A teoria dos afetos passa a ser reinterpretada. Para os apologistas do Realismo "os movimentos da alma" podiam ser detectados e revelados através de um meio - a música - e assim ser descritos como que pertencentes a uma natureza visível (Dahlhaus, 1985, p. 16-29). Uma consequência óbvia destas observações é a relação que Hatch (1986, p. 189) aponta sobre como Dahlhaus percebe e explica a ligação entre realismo musical e nacionalismo, Dahlhaus escreve que

realismo musical e nacionalismo estão inextricavelmente associados no século XIX, ao ponto que "entonações" musicais, as quais sempre são as entonações de uma língua nacional, representam um critério para o estilo realista...a única maneira da música alcançar o realismo é se apropriando da substância musical de uma linguagem, e a ideia que a originalidade de um compositor deva ser baseada no 'espírito popular', se for para ter alguma substância, são, no século XIX, a era de ambos, realismo e nacionalismo, dois lados da mesma moeda (Dahlhaus, 1985, p. 101-102). ${ }^{4}$

Por outro lado, a vertente realista na literatura italiana, foi adotada no movimento operístico do Verismo. Neste, a tendência era a de se procurar uma abordagem que lidasse com a realidade contemporânea da época. A estreia e o

\footnotetext{
${ }^{4}$ Por outro lado as críticas às ideias de Dahlhaus sobre realismo musical e sua associação com conceitos da sociologia, mais especificamente o conceito de "tipo ideal" de Weber, põe as questões levantadas por Dahlhaus em uma dura crítica (vide Gosset, 1989). Por outro lado, Frisch (2005) aponta a importância do movimento acerca do Naturalismo durante os últimos vinte e cinco anos do século XIX na Alemanha. Segundo Frisch "Naturalismo foi a primeiro movimento programático consciente do modernismo germânico. Ele teve seu início por volta de 1880, inicialmente em dois centros urbanos, Munique e Berlim, e começou a declinar no final da década de 1890" (p. 36). Mais adiante, Frisch também elucida que os termos Naturalismo e Realismo eram utilizados, por vezes, de maneira semelhante e invocando ideias parecidas, além de um forte sentimento nacionalista (p. 38).
} 
sucesso da Cavalleria rusticana de Pietro Mascagni em maio de 1890 em Roma5 certamente chamou a atenção de Nepomuceno, então estudante no Liceo Musicale Santa Cecília. No Liceo, Nepomuceno teve como professor de piano Giovanni Sgambatti (1841-1914), um defensor e incentivador da música não operística italiana. A decisão de Nepomuceno em deixar Roma em agosto de 1890 e matricular-se na Academia Meister Schulle, em Berlim, para estudar com Herzogenberg, mostra a tendência de aceitação da estética germânica como norteadora. Também ilustrativo deste ponto de vista é o relatório elaborado por Miguez em 1897. No documento realizado após sua viagem de visita aos conservatórios musicais europeus, a conclusão, óbvia, considerava as instituições italianas conservadoras e ultrapassadas, e as suas contrapartes alemãs, progressistas e inovadoras (vide Pereira, 2007, p. 75-76; e Vermes, 2004). Nas palavras de Miguez:

Verdade é que nas escolas oficiais italianas predomina um conservatorismo impertinente, os mesmos antigos e obsoletos métodos são ainda estritamente observados; ao aluno veda-se toda a liberdade para desembaraçar-se de uma infinidade de peias sem utilidade, e, contrariamente ao que se faz em outros países, notoriamente na Alemanha, persiste-se em condenar a priori todo e qualquer método evolutivo. O que não resta dúvida é que um fenômeno qualquer dá-se na Itália desde a aparição tumultuosa de Rossini, a quem cegamente adoram como um gênio, sem rival no passado, no presente e... no futuro! [...] Dir-se-ia que vai pouco a pouco vencendo a medonha crise e levantando-se a alturas que não é possível prever desde já, vendo artistas como Martucci, o inteligente diretor do Liceu de Bolonha. Sgambatti, o eminente pianista e compositor discípulo de Liszt, Verdi nas suas últimas obras, e de alguma forma Puccini, Giordano e outros, volverem-se para a Alemanha e aí beberem sofregamente os mais salutares exemplos. Mas... victoriando e pondo em primeira plana aqueles que deixam-se absorver pelos processos de uma escola estrangeira, escola que é a antítese do sentimento nacional, ela, a Itália, reconhece ipso facto a sua decadência, com a que, aliás, não se conforma! Singular psicologia a de um povo na última fase do seu crepúsculo!... (Miguez, 1897, p. 30, apud Vermes, 2004)

Os ideais estéticos germânicos e franceses do final do século XIX, voltados para a objetividade da ciência, do positivismo e do Realismo literário, o

\footnotetext{
${ }^{5}$ Seguiram-se as estreias em Hamburgo, em janeiro de 1891, e no Rio de Janeiro, Teatro Lírico, em setembro de 1891 (Kobbe, 1991, p. 377; e Frisch, 2005, p. 63).
} 
abolicionismo e o Republicanismo, dominam as opções ideológicas no Brasil a partir de 1870. A primeira transposição dessa realidade em termos de consciência cultural se deve à "Escola do Recife", em particular a Tobias Barreto (Bosi, 2006. p. 164-165). Romero sumariza:

Positivismo, evolucionismo, darwinismo, crítica religiosa, naturalismo, cientificismo na poesia e no romance, folclore, novos processos de crítica e história literária, transformação da intuição do Direito e da política, tudo então se agitou e o brado de alarma partiu da Escola de Recife (Romero, 1926, p. XXIII-XXIV, apud Bosi, 2006, p. 166).

A ligação de Nepomuceno com Tobias Barreto, líder da "Escola do Recife", nos remete a uma conexão com as novas ideias surgidas a partir de 1870. ${ }^{6}$ Em 1881 Nepomuceno passa a frequentar a Faculdade de Direito do Recife e a ter um contato direto com Tobias Barreto, estudando com ele filosofia e alemão (Corrêa, 1996, p. 12; vide também Pereira, 2004, p. 75). As atividades abolicionistas e republicanas de Nepomuceno, entre 1882 e 1885 , são bem conhecidas. ${ }^{7}$

As tendências realistas que Nepomuceno pode ter observado na literatura e na estética da sua época são sumarizadas por Bosi, que aponta dois níveis onde o Realismo na literatura brasileira é teorizado de maneira mais contundente:

distanciamento do fulcro subjetivo é a norma proposta pelo Realismo literário. A atitude de aceitação da existência tal qual ela se dá aos sentidos desdobra-se, na cultura da época, em planos diversos mas complementares: a) - no nível ideológico, isto é, na esfera da explicação do real, a certeza subjacente de um Fado irreversível cristaliza-se no determinismo (da raça, do meio, do temperamento [...]);

\footnotetext{
${ }^{6}$ Tobias Barreto de Menezes (1837-1889), jurista e líder da Escola do Recife. Entre 187181 escreve em periódicos liberais enfatizando as ideias dos positivistas franceses e dos monistas alemães.

${ }^{7}$ Também é importante lembrarmos da relação entre Nepomuceno e os irmãos Bernardelli, Henrique (1857-1936) e Rodolfo (1852-1931), e com Machado de Assis em 1886, já no Rio de Janeiro. É importante lembrar que Memórias Póstumas de Brás Cubas data de 1881 e é um marco no Realismo machadiano.
} 
b) - no nível estético, em que o próprio ato de escrever é o reconhecimento implícito de uma faixa de liberdade, resta ao escritor a religião da forma, a arte pela arte, que daria afinal um sentido e um valor à sua existência cerceada por todos os lados. O supremo cuidado estilístico, a vontade de criar um objeto novo, imperecível, imune às pressões e aos atritos que desfazem o tecido da história humana, originam-se e nutrem-se do mesmo fundo radicalmente pessimista que subjaz à ideologia do determinismo (Bosi, 2006, p. 167-168).

Coutinho, por sua vez, elenca oito características que definem Realismo em geral:

1. O Realismo procura apresentar a verdade. Esse tratamento verdadeiro do material, essa verossimilhança no arranjo dos fatos selecionados, unificados, apontando numa direção, é essencial. 2. O Realismo procura essa verdade por meio do retrato fiel de personagens. 3. O realismo encara a vida objetivamente. 4. O Realismo fornece uma interpretação da vida. Retratando objetivamente a vida, o Realismo, todavia, dá-lhe sentido, interpreta-a. A acumulação de fatos, pelo método da documentação, não é tudo na atitude realista: a seleção e a síntese operam buscando um sentido para o encadeamento dos fatos. Daí a preferência pela narração em vez da descrição. 5. O Realismo retrata a vida contemporânea. [...] Ele encara o presente, [...] na política [...]. Qualquer motivo de conflito do homem com seu ambiente ou circunstantes é assunto para o realista. 6. O Realismo retira a maior soma de efeitos do uso de detalhes específicos. 7. A narrativa realista move-se lentamente. Pela própria natureza da técnica, que é minuciosa, o realista dá a impressão de lentidão, de marcha quieta [...] 8. O Realismo apóia-se sobretudo nas impressões sensíveis, escolhe a linguagem mais próxima da realidade, da simplicidade, da naturalidade (Coutinho, 1969, p. 6-8).

Na seguinte análise da Série Brasileira observa-se e enfatiza-se elementos de Realismo em música, considerando-se uma narrativa implícita na obra e que Nepomuceno realça através de elementos estruturais na sua obra. Em suma, a argumentação desta análise é direcionada para a identificação desta retórica realista nesta obra de Nepomuceno. 
II.

A Série Brasileira (1891) contém os seguintes movimentos: 'Alvorada na Serra', 'Intermédio', 'Sesta na Rede' e 'Batuque'. Duas destas peças são derivadas de obras anteriores de Nepomuceno. O "Intermédio" utiliza material do "Intermezzo" do Quarteto para cordas n. 3 de 1891, e o "Batuque" é uma orquestração da Dança de Negros composta em 1887. Nas peças da Série Brasileira Nepomuceno retrata em música fatos relacionados à natureza, tais como o alvorecer da manhã na montanha, um canto de pássaro, além de imitações de danças e costumes sociais, tais como o maxixe e o balançar de uma rede, e até mesmo produz uma mimese de dança na última das peças, "Batuque”, inserindo música alegadamente de caráter afro-brasileiro. A Série Brasileira corretamente pode ser considerada como um retrato da natureza e da sociedade brasileira da sua época. Ademais, leituras das obras de Nepomuceno que buscam correlação em obras de compositores contemporâneos seus são frequentes. No entanto, não se deve limitar a leitura a este tipo de indagação com o perigo de uma simplificação, por vezes demasiada, de uma possível contextualização e

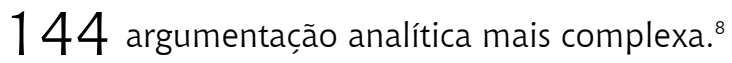

Luiz Heitor apresenta uma descrição dos elementos que podem ser considerados de cunho nacionalista na obra de Nepomuceno. Ele escreve:

A Série Brasileira, malgrado a singeleza, quiçá mediocridade da orquestração, fica sendo na música brasileira o marco inicial da orientação nacionalista [...]. Nas quatro peças que a integram o compositor emprega temas brasileiros ou os tipos de melodias e ritmos que caracterizam nossa música. Na página descritiva inicial, Alvorada na Serra, faz intervir o tema sapo-jururu, que tem sua origem no bumba-meu-boi nordestino, espécie de auto popular, representado e dançado no meio da rua. No Intermezzo, de um espírito esfuziante, aparece a linha buliçosa de certo maxixe muito em voga, no Rio. A Sesta na Rede tem na moleza cálida das horas de sol a pino, quando, adormentada pelo brando afago da brisa, a gente nordestina busca preguiçosamente a rede, e se entrega ao seu leve e sonolento embalo; há um misto de sensualidade e nostalgia nessas páginas de uma poesia penetrante, em que o ritmo das cordas evoca o movimento característico da rede,

${ }^{8}$ Por exemplo, a "Alvorada na Serra" pode encontrar paralelos em "Alvorada" da ópera Lo schiavo (1889) de Carlos Gomes, e na primeira peça de Peer Gynt, Suite n. 1 (1874-5) de Edvard Grieg. 
fazendo ranger os ganchos que a sustentam; é, na Série Brasileira, o número cujo nacionalismo se conserva impalpável, pois não reside na adaptação de fórmulas musicais; concentra-se, todo, na evocação do quadro tipicamente brasileiro. O Batuque final, com o colorido sombrio e as graves batidas sincopadas do início transformando-se, pouco a pouco, na orgia de sons e de ritmos do doppio movimento, conseguiu popularizar-se mais ainda do que os números precedentes; a subtileza da arte de Nepomuceno revela-se no partido que ele soube tirar de um simples motivo intensivamente sincopado, mas sem muita caracterização melódica; por meio de modulações e de transformações rítmicas ele mantém em suspenso o ouvinte, conduzindo-o às mais variadas e surpreendentes gradações, até atingir a explosão final (Azevedo, 1956, p. 166-167).

No entanto, Squeff tem observado a insistência equivocada dos musicólogos brasileiros em atribuir importância à música de Nepomuceno somente pela sua tendência nacionalista (Squeff, 2001, p. 33). De fato, o nacionalismo na música de Nepomuceno é somente um dos aspectos da sua ideologia, diretamente relacionado ao credo republicano de "Ordem e Progresso". De acordo com as crenças republicanas, a então recente República do Brasil tinha que ser mostrada ao mundo, e em particular à Europa, como uma nação progressista, que em sua história recente tinha abolido a escravidão (1888) da sua realidade. A abolição dos escravos significou para Nepomuceno a liberação para incluir música afro-brasileira na sua própria música, uma vez que os escravos, teoricamente, deixaram de ter um status inferior entre a população brasileira. Nepomuceno, portanto, deve ter se sentido livre para incluir na Série Brasileira ritmos sincopados, alegadamente oriundos de música afro-brasileira, e mostrado esta música à audiência europeia e brasileira como representante do seu país moderno e progressista. Carvalho, observando um artigo no Jornal do Commercio de 1906 e que atribui a Nepomuceno o título de fundador da música brasileira, resume esta ideia:

A primeira República, neste momento, está empenhada em uma política de transformação e afirmação do Brasil como uma nação civilizada, sendo que, para isso, é necessária a criação de um patrimônio artístico e cultural que represente esse desenvolvimento tão almejado. Essa ideia foi muito bem recebida pelos artistas da época, que se empenharam em fomentar o nascimento de artistas autóctones e incentivar as produções artísticas e culturais daqueles já consagrados ou dos que já haviam, de alguma forma, iniciado seu trabalho. 
Nepomuceno, jovem talento brasileiro, recém chegado do Velho Mundo, parece ser a figura ideal para servir como grande emblema desta República nascente e destas novas áreas de reforma nas artes brasileiras que pairavam no momento. Suas ligações políticas e suas amizades com grandes artistas da época - como os irmãos Bernardelli, Eliseu Visconti, Artur Azevedo e outros parecem ter sido fundamentais para sua alçada como figura central da música do período (Carvalho, 2003, p. 6-7).

Da mesma maneira, entende-se que as influências europeias presentes na música de Nepomuceno, também refletem esta ideologia. Como um homem do seu tempo, um cosmopolita, Nepomuceno apresentou na sua obra as diversas tendências estéticas da sua época, incluindo aí conotações descritivas, sociais e políticas.

\section{III.}

Na seguinte análise da Série Brasileira observa-se e enfatiza-se elementos de Realismo em música.

\section{Alvorada na Serra - "natureza criativa"}

Na primeira peça, "Alvorada na Serra”, considerando-se o título descritivo que Nepomuceno dá à sua peça, tem-se um direcionamento para uma representação de imitação da natureza (imitatio naturae) através da imitação de sons não musicais (canto do sabiá); de movimento temporal, analogia entre o amanhecer e a passagem do tempo; de "pintura musical" (Tonmalerei ou Wortbildung aus Naturlauten); e de natureza criativa (Natura naturans).

A peça é uma representação pictórica do alvorecer nas montanhas. A descrição que, talvez, Nepomuceno tenha almejado representa através de vários parâmetros musicais, muito bem delimitados, os elementos sonoros capazes de refletir uma imitação da natureza criativa, ou como Dahlhaus se refere, natura naturans.

O Exemplo 1 ilustra a apresentação da primeira frase do tema (Sapo cururu) no oboé, a qual é acompanhada de uma intervenção na flautas e de uma nota pedal nas trompas (c. 1-13). A melodia é desenvolvida brevemente no oboé entre os c. 7-13, e contempla, no c. 8, a introdução de uma síncope que já nos 
remete a um elemento folclórico nacional, no entanto esta sensação é interrompida ao apresentar-se os intervalos de 4a justa entre lá e mi, com sua finalização por grau conjunto descendente, em sol. A repetição deste último motivo, reforça o caráter bucólico da melodia, e também o caráter serrano do início da obra. Pela sua terminação, esta primeira apresentação da melodia chega a expor um caráter mais modal do que tonal, portanto de caráter pastoral e até mesmo mais "primitivo". O pedal nas trompas cumpre uma função sintática de repouso, de falta de movimento, o que pode-se associar à ideia de primitivo ou estático, no contexto da peça, de uma falta de movimento temporal e espacial. Assim, o pedal desempenha uma função que se refere a um tema ainda não desenvolvido e até mesmo com uma conotação de "primitivo".

Exemplo 1 “Alvorada na Serra”, c. 1-13

I. Alvorada na Serra
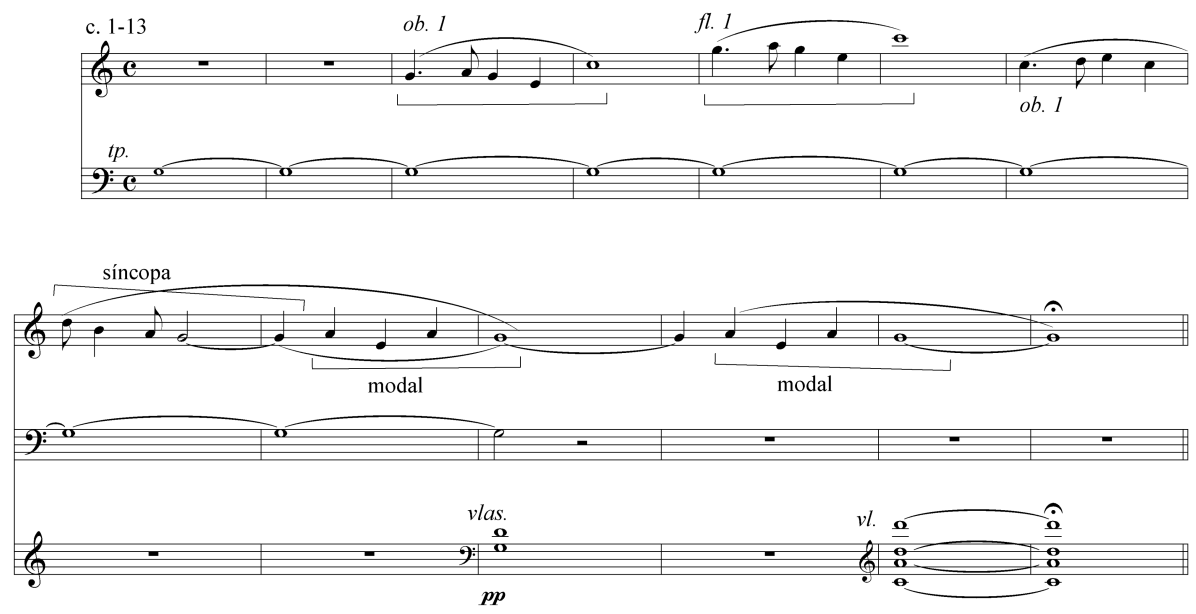

Já a segunda apresentação da melodia inteiramente na 1a flauta solo (Exemplo 2), c. 14-21, torna-se mais tonal pelo acompanhamento das cordas, mas uma terminação tonal é decisiva no caráter desta apresentação da melodia. Um pedal de tônica nas violas também apresenta a tendência de centralizar a tônica. Aqui a textura também muda, o acompanhamento nas cordas apresenta a melodia devidamente harmonizada na tônica e a textura de contraponto de nota contra nota provê outra sonoridade para a melodia. 
Exemplo 2 "Alvorada na Serra”, c. 14-21

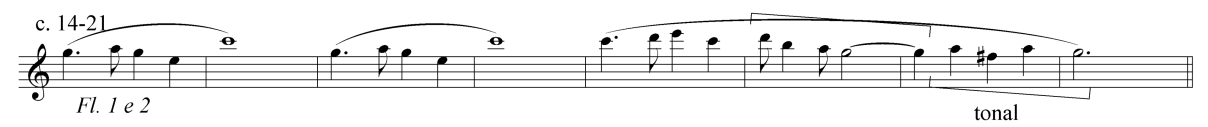

Um processo imitativo inicialmente entre clarinetes e oboés. c. 21-29, culminará em uma primeira e afirmativa apresentação ff do tema. O processo para chegarmos até esta apresentação inicia-se no c. 21, com as imitações nos sopros, até que nos c. 25-29 a melodia completa apresentada no clarinete é imitada pelo oboé.

O próximo estágio, ilustrado no Exemplo 3, é o adensamento da textura (c. 29-43) com a entrada dos trompetes com uma figuração de mínimas, sobre o pedal de dominante nos violoncelos, e as imitações do início do tema, nos sopros (clarinetes e oboés) e nas cordas ( $1^{\text {os }}$ e $2^{\text {os }}$ violinos). A partir do compasso 38 ocorre um redução progressiva do motivo inicial até sua completa liquidação e transformação em trinado no c. 43.

Exemplo 3 "Alvorada na Serra", c. 34-43
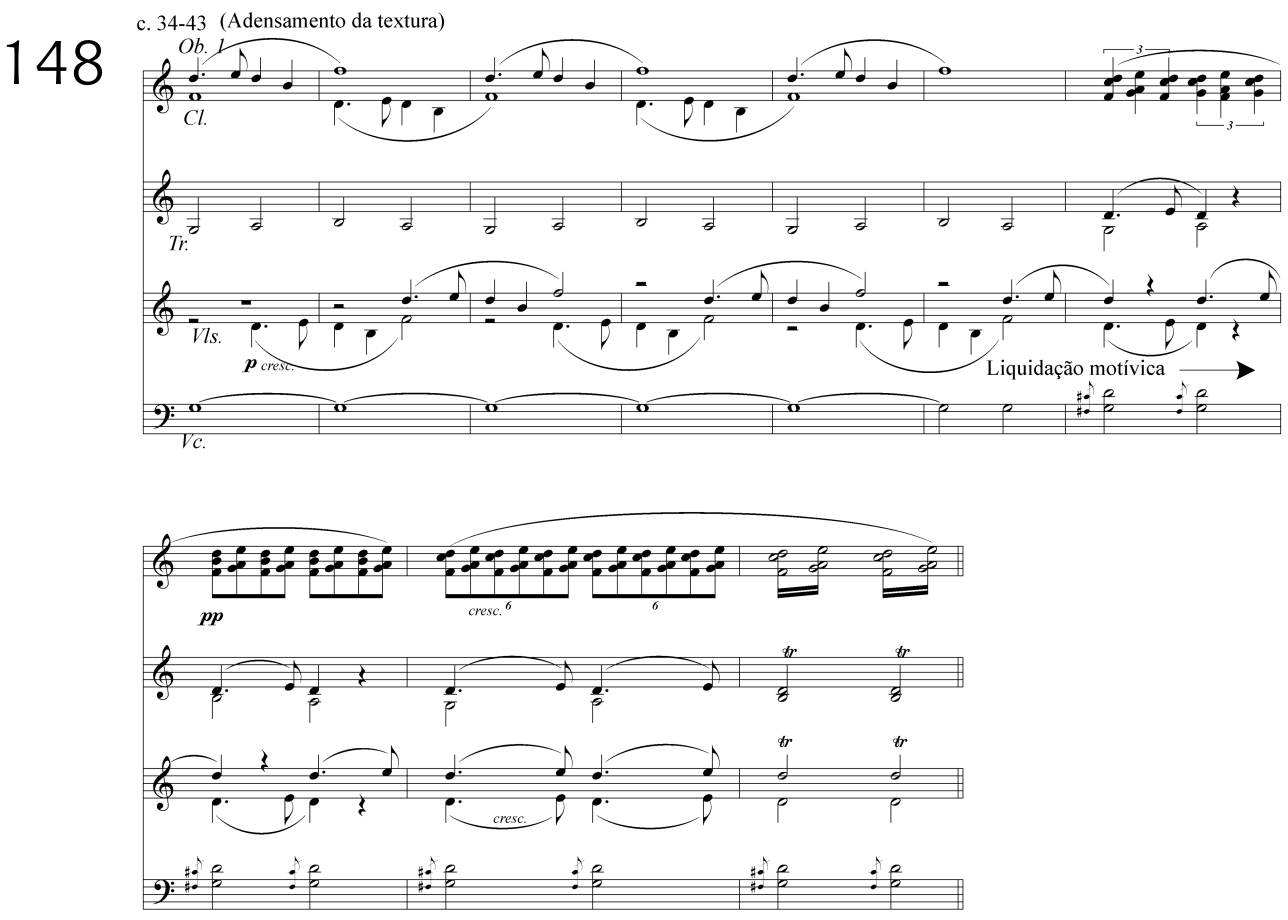
Ao atingir uma apresentação $f$ do tema (c. 44), inicia-se um processo de preparação para a apresentação de um ponto importante dentro da narrativa elaborada por Nepomuceno: o canto do sabiá. Este processo inicia-se com a apresentação da melodia inicial com uma textura orquestral mais densa (c. 4447), (cordas, trompetes, trompas, fagotes, clarinetes, oboés e flautas). Um processo de redução motívica (c. 48-51) também é elaborado até o ponto de modulação de Dó maior para Lá maior (c. 52), que por sua vez conduzirá, através de uma linha do baixo cromática ascendente (lá-láb-si), a Ré maior, a tônica temporária do início da seção de apresentação do canto do sabiá. Um novo processo de liquidação motívica ocorre entre os c. 67-74 (vide Exemplo 4). Segue uma breve passagem por Ré maior, enfatizando arpejos na harpa e a subsequente apresentação do canto do sabiá, primeiramente em Lá menor, passando por Ré menor e, finalmente, em Dó maior.

Exemplo 4 "Alvorada na Serra”, c. 44-51, c. 67-74

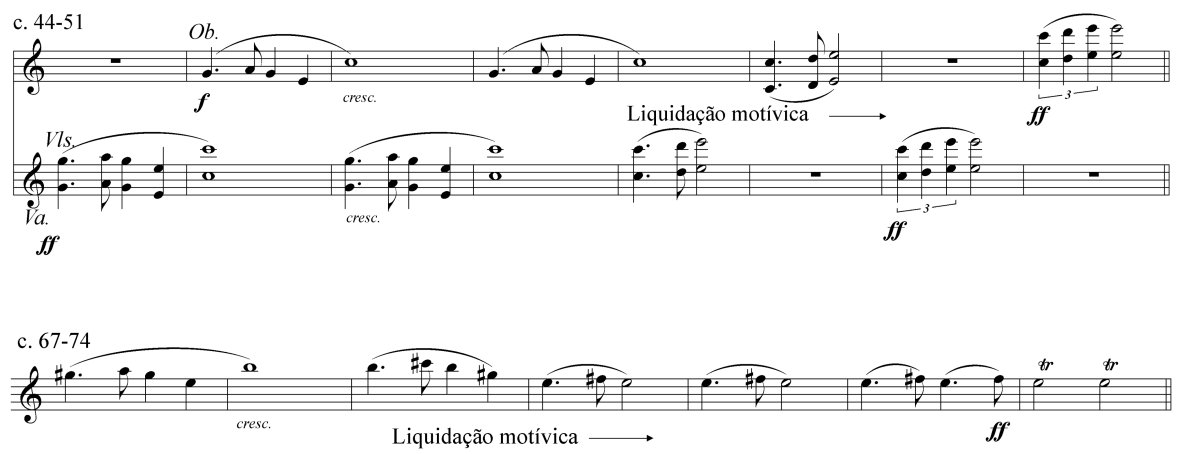

Até este ponto a narrativa musical de Nepomuceno é extremamente clara e de fácil percepção. Uma narrativa com elementos que remetem à natureza em criação (o amanhecer), à elementos do folclore (sapo cururu), à pintura musical (Tonmalerei), à imitação de sons não musicais (canto do sabiá), e ao aspecto de deslocamento temporal (o avançar do amanhecer). O “cuidado estilístico, a vontade de criar um objeto novo, imperecível", a que Bosi se refere, ocorre na segunda seção da peça de Nepomuceno.

A seção B da peça, Molto Moderato, reaproveita o material do canto do sabiá para uma elaboração de motivos musicais. Assim Nepomuceno consegue 
associar sons não musicais (o canto do sabiá) à elaboração musical e dar à sua obra uma conotação estética de arte pela arte, de elaboração do material musical de maneira sofisticada. A transformação motívica, c. 94-107, com reaproveitamento do material do canto do sabiá não se fixa como material principal da seção (Exemplo 5). No entanto, este reaproveitamento de material temático representa a inventividade do compositor e, portanto, seu esmero estético e técnico.

Exemplo 5 "Alvorada na Serra”, canto do sabiá, c. 94-100

Zanto do Sabiá)
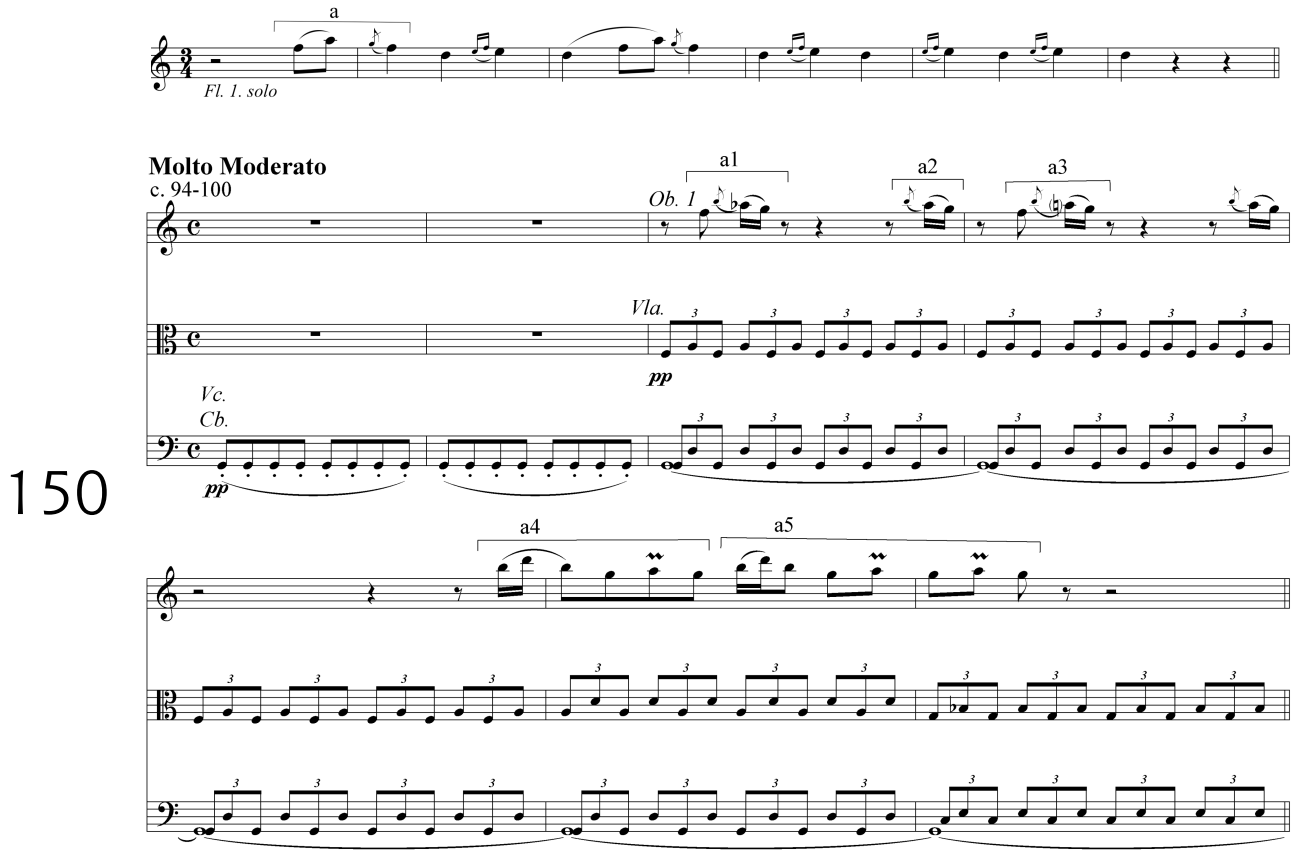

O material temático principal da seção entre os c. 108-165 é um tema novo, inicialmente apresentado no registro grave dos violinos. A melodia é apresentada com antecedente e consequente assimétricos (5 +3 compassos) (c. 108-115), e que subsequentemente sofrem uma variação e um processo de elaboração motívica próximo ao de variação progressiva, o que assegura uma conexão motívica com o material seguinte (c. 116-136). O trabalho motívico é indicado, no Exemplo 6, pelas setas ligando segmentos numerados de 1 a 9 e que 
têm relação motívica próxima. O movimento de registro é do grave para o agudo e move-se de Dó maior (c. 108-124) para Sol sustenido maior (c. 129-142). Uma breve interrupção em Dó maior reapresenta o tema principal da seção, mas novamente segue uma subseção, a tempo, que inicia o retorno à tônica inicial, Dó maior, e à Seção $A^{\prime}$.

Exemplo 6 "Alvorada na Serra”, c. 108-136
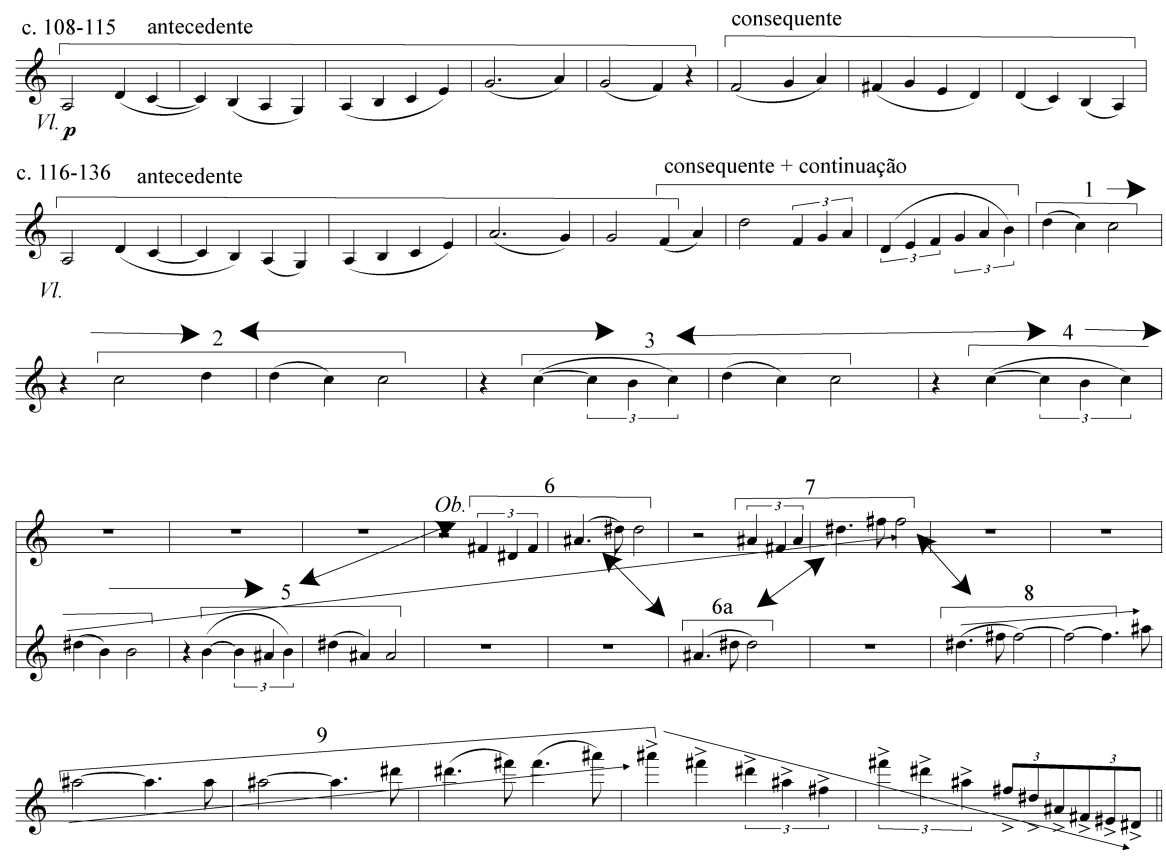

A seção A' (c. 166-190), é bastante abreviada em relação à seção inicial. No entanto, todos os elementos marcantes da primeira seção estão presentes: 1. 0 início da canção folclórica; 2. A apresentação da melodia inicial sem uma definição muito clara da tônica; e c. A citação do canto do sabiá.

Intermédio - "O popular apresentado de maneira culta"

O Intermédio deriva seu material básico do terceiro movimento do Quarteto para cordas n. 3. ${ }^{9}$ Mas o desenvolvimento que este material sofre é

\footnotetext{
9 Apesar de boa parte do material deste movimento ser derivado do "Intermezzo" do Quarteto para cordas n. 3, a reconstrução deste material por Nepomuceno é bastante significativa, em especial a adaptação à forma sonata.
} 
grande, e engendra elementos que podem ser compreendidos como ligados a uma estética de caráter nacional ou como aponta Mário de Andrade:

Se observe como no "Batuque" (A. Nepomuceno, "Série Brasileira", n 4, ed. C. Arthur Napoleão) certa frase repetida sempre pelas cordas, apresenta a síncopa obrigatória em todos os tempos, vai em progressão porém ascendente. É uma frase sem caráter, possuindo a retórica nacional mas não possuindo nacionalidade. Uma falsificação nacional. Já porém no Intermédio ( $\mathrm{n}^{\circ} 2$ da mesma peça), certos arabescos em destacado, descendentes, (comps. 15 a 18-, são bem mais característicos apesar de não trazerem síncopa (Andrade, 1972, P. 47, nota 1).

No entanto, o quão nacionalista é a música da Série Brasileira, em particular no Intermédio e no Batuque é discutível. A utilização de elementos rítmicos sincopados e melodias derivadas de ritmos populares, parece não corroborar a ideia de nacionalismo em uma obra que tem por característica geral a representação e a manifestação de valores nacionais, sociais e políticos. É neste sentido que o Intermédio parece ser menos interessante se visto em termos de uma expressão de caráter nacionalista e mais interessante se observado do ponto de vista de uma representação de um aspecto social da época de seu compositor. Notável, portanto, torna-se a melodia da seção Più Lento da peça. A melodia é centrada em Fá sustenido menor e apresentada pelo oboé, e recebe a indicação de sentito. O que se destaca nessa melodia é sua constante reiteração da figura sincopada e de frases longas, o que propicia o sentido de uma melodia fluente e característica de dança popular, especificamente de um maxixe. Importante para o caráter do trecho é o acompanhamento orquestral que com sua constância rítmica, nos lembra um acompanhamento de Habanera. Aliás, segundo Mário de Andrade, "foi da fusão da habanera, pela rítmica, e da polca, pela andadura, com a adaptação da síncopa afro-lusitana que originou-se o Maxixe" (Andrade, 1989, p. 317). Estes dois elementos recorrem no Intermédio de maneira estrutural, o primeiro como característica do acompanhamento, e o segundo, na melodia apresentada pelo oboé. O Exemplo 7 ilustra a passagem. 


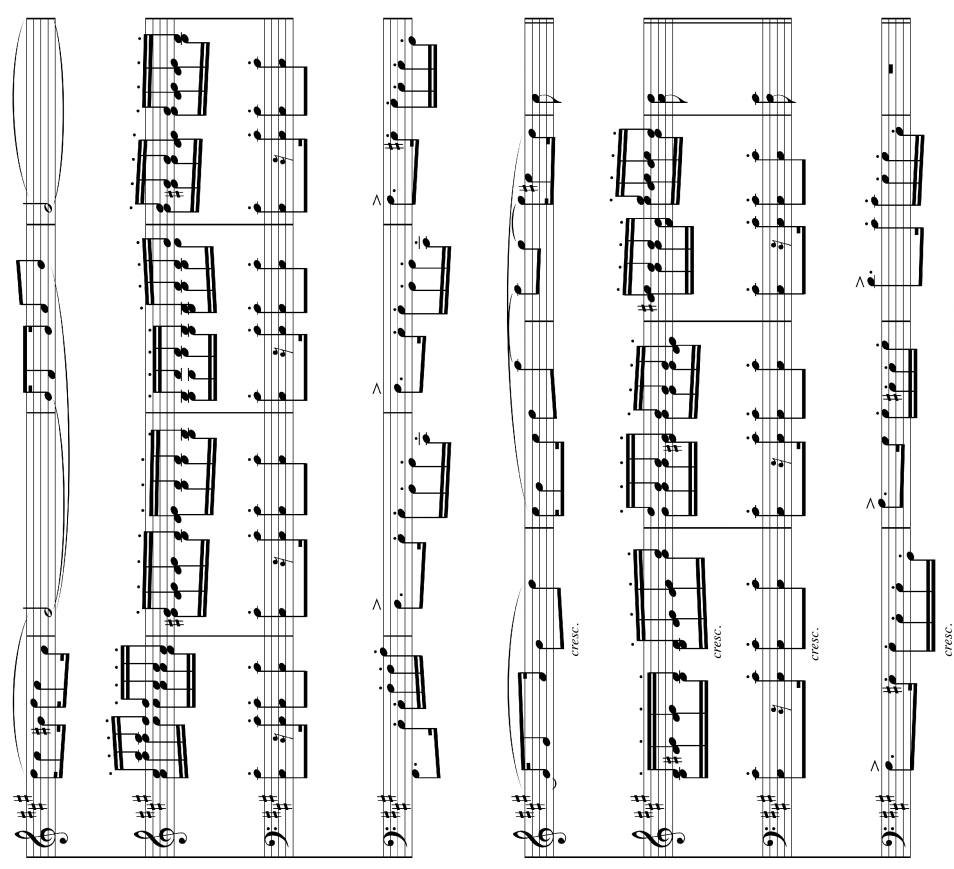

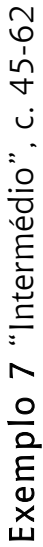

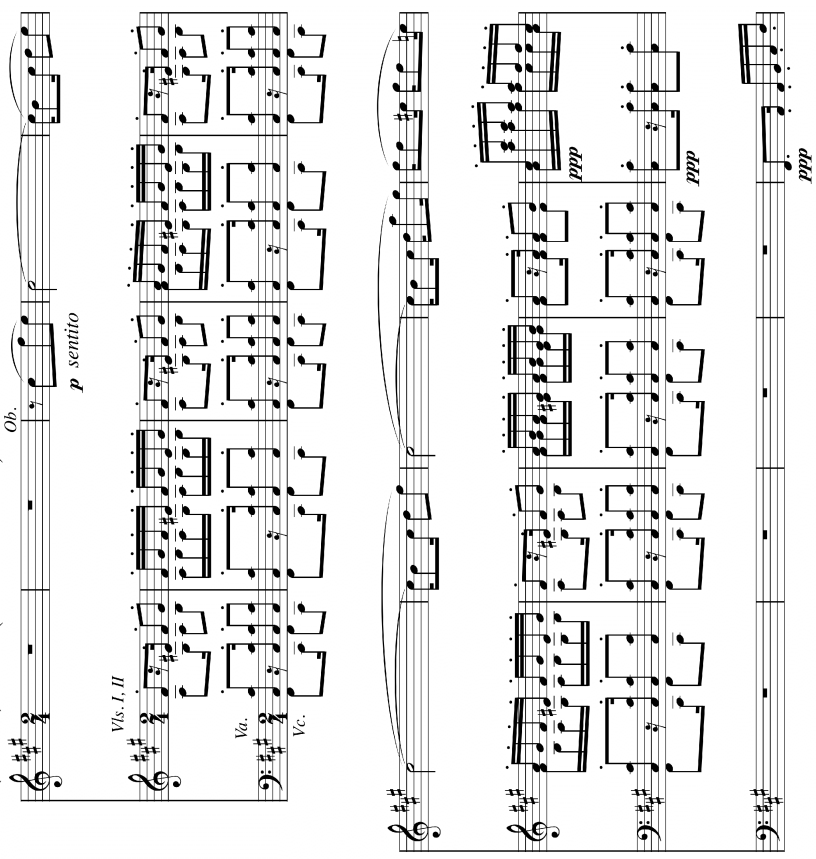


$\mathrm{O}$ aspecto mais interessante deste movimento, no entanto, refere-se à adaptação que Nepomuceno faz na utilização destes elementos na forma sonata. A apresentação dos dois temas correspondem aos temas em uma organização de exposição de forma sonata: $1^{\circ}$ tema em Lá maior e reapresentado em Fá sustenido menor (c. 1-36), transição (c. 37-44.1), e $2^{\circ}$ tema em Fá sustenido menor (c. 44104). A seção central de desenvolvimento corrobora a leitura da forma sonata do movimento. Esta seção apresenta um desenvolvimento dos elementos temáticos apresentados na exposição e de maneira significativa apresenta uma seção de retransição (c. 148-159), cumprindo, assim, com as funções sintáticas da seção correspondente da forma. Importante nesta seção é o prolongamento da harmonia de V/V de Lá maior que, no entanto, não é resolvida no V de Lá, mas que sofre uma elisão do acorde de V, e a resolução cadencial se dá já no início da reexposição onde o baixo da tônica (Lá menor) é mi (V) (Exemplo 8). A reexposição, por sua vez, apresenta a resolução tonal dos dois temas na tônica, $1^{\circ}$ tema em Lá maior, e $2^{\circ}$ tema em Lá menor. O início da reexposição ainda apresenta imitações do $1^{\circ}$ tema entre a sua exposição no violoncelo e a da flauta, mais um aspecto da técnica composicional adquirida por Nepomuceno e sua 154 intenção de apresentar o popular e o social de uma maneira refinada dentro da narrativa musical da obra. A coda final em tempo Vivo fragmenta o motivo inicial do $1^{\circ}$ tema e é interrompida ao fazer menção ao ritmo de acompanhamento da melodia de maxixe e de retorno ao Tempo $1^{\circ}$ (c. 258-261).

A retórica que Nepomuceno propõe neste movimento é, em primeiro lugar, a de uma inserção de elementos que fazem referência à música de caráter nacional, em segundo, dentro da dialética da música europeia. O primeiro, representa o seu país, o nacional, a realidade de aspectos sociais representados pela dança, em particular, o maxixe, o segundo, a tentativa de mostrar esta realidade de acordo com a tradição europeia de "música culta" ao utilizar a forma sonata. 
Exemplo 8 "Intermédio", c. 157-165

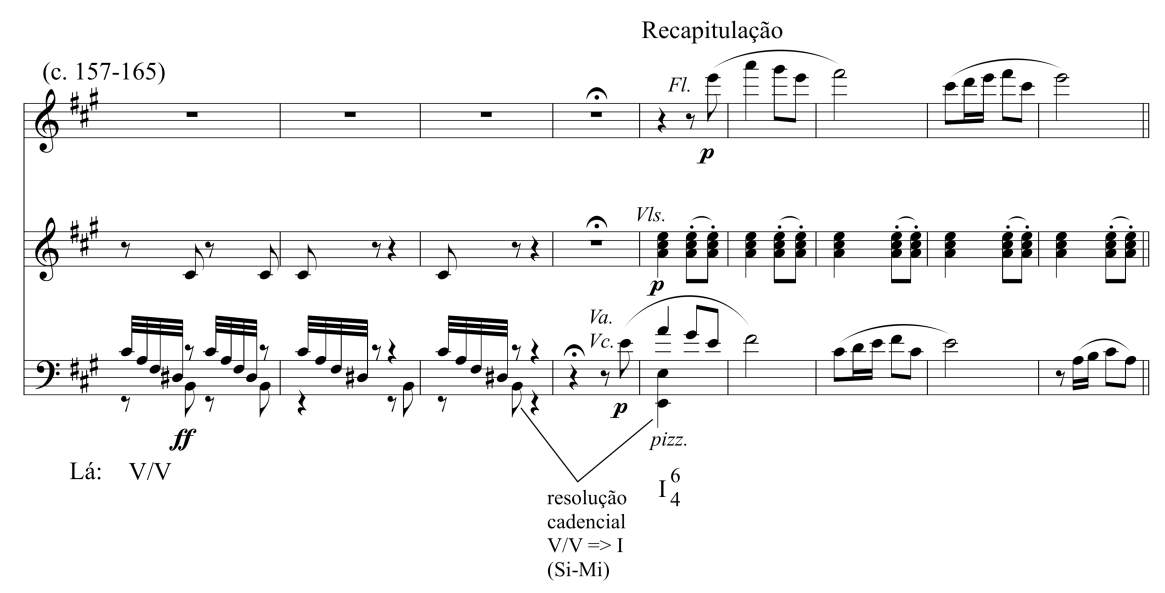

Sesta na Rede - "o social"

A terceira peça da Série Brasileira retoma o caráter descritivo. Como o título dado ao movimento sugere, o balançar de uma rede é evocado durante grande parte da peça. A estrutura do movimento remete a uma relação com o primeiro movimento, uma forma ternária $\mathrm{A}-\mathrm{B}-\mathrm{A}^{\prime}$, onde a seção central, no caso desta peça, apresenta um contraste gerado pela derivação do tema principal do movimento. Elementos estruturais da peça contribuem para o sentido de monotonia que está implícito no movimento constante do balanço de uma rede. O onze primeiros compassos da peça apresentam elementos estruturados de maneira a não produzir ou representar qualquer sentido de movimento: 1 . Nota pedal nos violoncelos; 2. A utilização de harmonias estáticas, sem variação; e 3. A apresentação do tema da peça, primeiramente na flauta e depois no oboé, caracterizando uma melodia bucólica pela sua singeleza. O Exemplo 9 ilustra os aspectos da passagem. 
Exemplo 9 "Sesta na Rede”, redução dos c. 1-6

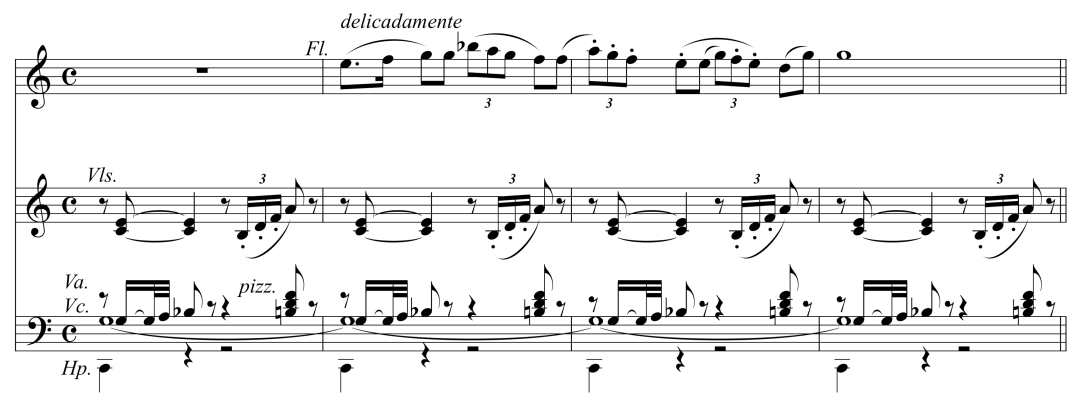

Uma pequena variação é introduzida na seção entre os c. 12-24, ao modificar o ponto focal da harmonia para Lá bemol Maior $\left(V^{7}-\mathrm{ii}^{7}\right.$ e $\left.\mathrm{i}^{6 / 4}\right)$, depois Lá menor $\left(V^{7}-\mathrm{ii}^{7}\right)$, e posteriormente Dó maior, o compositor cria a sensação de movimento. Juntamente com o movimento harmônico, Nepomuceno modifica a figuração que representa o balançar da rede, e acrescenta um fragmento do tema da peça, apoiado pelas notas pedal Mi bemol, e posteriormente Mi natural; notável também é o aproveitamento enarmônico entre Lá bemol como Sol sustenido para conduzir a tonalidade para Lá menor (vide Exemplo 10). Um

156 retorno a Dó maior e uma reapresentação do tema da peça encerram a primeira seção do movimento. Por outro lado, é possível referir-se a um intento de Nepomuceno em "modalizar" a harmonia da peça. O uso do sétimo grau abaixado em Dó maior (si bemol) e de Mi bemol maior (ré bemol) provoca naturalmente uma ambiguidade tonal que por sua vez também contribui para o sentido de monotonia, de falta de direcionamento harmônico, na peça.

Exemplo 10 "Sesta na Rede", redução harmônica c. 1-24

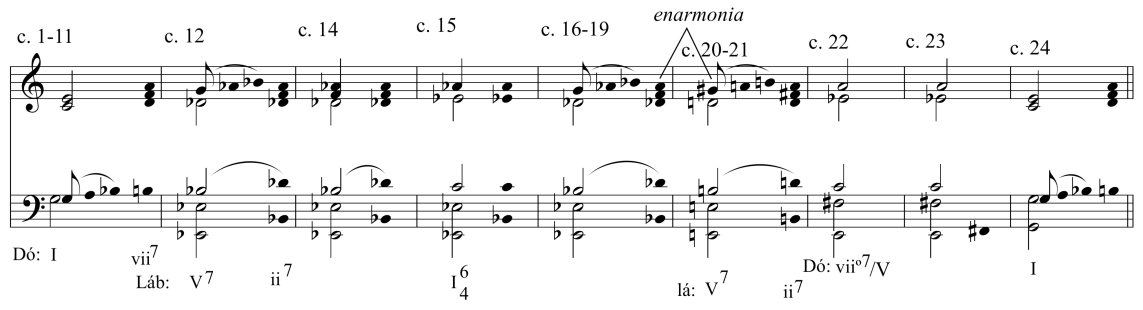


A seção central (c. 32-51), Un poco più Presto, em Lá menor, interrompe o sentido estático e monótono da primeira seção. A textura é mais densa e um fragmento do tema inicial é enfatizado. A progressão harmônica é mais dinâmica e direcional, e aponta para a cadência ad. libitum da flauta solo. O Exemplo 11 ilustra uma redução da harmonia do trecho.

Exemplo 11 “Sesta na Rede", redução harmônica c. 32-47

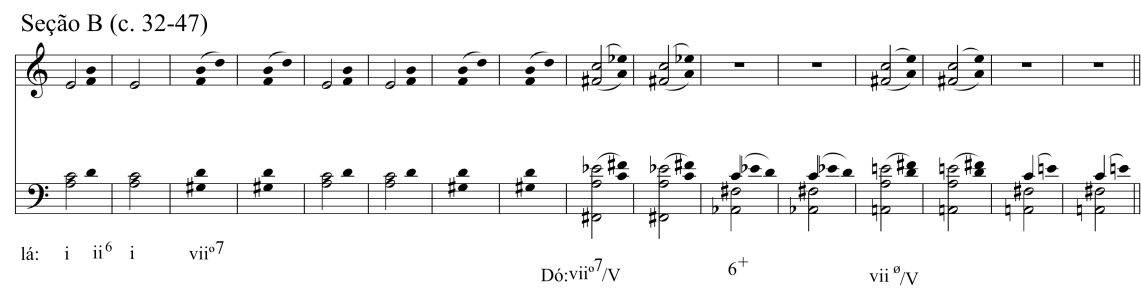

O retorno ao material inicial na seção $A^{\prime}$ restaura a tranquilidade e monotonia que caracterizam o balançar da rede.

A inventividade de Nepomuceno nesta peça se mostra grande, desde a utilização de notas pedal, e harmonias estáticas para representar o balanço da rede, até a produção de um movimento harmônico com a intenção de promover contraste e variação. O uso destes elementos parece ser propositada e com uma intenção clara de representação de um aspecto social: o costume de descansar na rede, frequente na região nordeste do Brasil.

\section{Batuque - "O Negro e aspecto político"}

Dahlhaus observa que imitação da natureza tornou-se uma interpretação alternativa para mimese, que tem seu sentido original ligado à imitação de uma ação, especialmente por meio da dança, mas que se pode depreender como a representação ou imitação do mundo real na arte e na literatura (Dahlhaus, 1985. p. 17). O Batuque, quarto movimento da Série Brasileira, apresenta um modelo de imitação de expressão de música de origem africana. Uma das características da dança, batuque, é a constante aceleração, como é descrita por Mário de Andrade: 
aceleram-se, conforme a música se torna mais viva e arrebatada, e, em breve, se admira um prodigioso saracotear de quadris que chega a parecer impossível poder-se executar sem que fiquem deslocados os que a ele se entregam (Andrade, 1989, p. 54). ${ }^{10}$

A imitação que Nepomuceno propõe encontra respaldo na descrição acima e na própria situação político/social da época da composição de sua peça. $\mathrm{O}$ envolvimento de Nepomuceno com o movimento abolicionista data de cerca de 1882-85 e, certamente, tornou-se uma das convicções do compositor a ponto dele compor sua Dança de Negros em 1887, como uma referência à música de caráter afro-brasileiro e uma espécie de manifesto musical a favor do movimento abolicionista. Esta peça foi incluída na Série Brasileira e orquestrada recebendo o título de Batuque, chamando a atenção a inclusão de uma seção de percussão que inclui reco-reco, triângulo, bombo e pratos.

Por outro lado, o que Squeff observa como uma liberação para a utilização de elementos afro na música de Nepomuceno, ou seja, o escravo liberto, de certa maneira, libertou também o(s) compositor(es) para a utilização destes elementos nos salões da sociedade e Nepomuceno percebeu essa possibilidade ao compor seu Batuque (vide Squeff, 2001, p. 51). O gesto de dança afro-brasileira que permeia a peça está presente na própria estrutura musical de Batuque. A peça é estruturada em duas grandes seções, a primeira apresenta um tema introdutório caracterizado por um movimento ascendente seguido de um tema caracterizado por síncopas (Exemplo 12). O movimento constante de repetição caracteriza, também, o gesto de música percussiva de origem afrobrasileira que tem a intenção de produzir êxtase.

A única variação que Nepomuceno introduz é relativa à harmonia. Este tema passa pelas regiões de Dó maior, Mi menor/maior, Dó maior, transição (c. 50-52), Mi maior, nova transição (c. 62-65), e Fá maior. A chegada a Fá maior prepara e introduz a tonalidade da segunda parte da peça.

\footnotetext{
${ }^{10}$ Sobre a origem e a prática de danças na corte imperial no Rio de Janeiro, vide Magaldi, 2004, p. 105-112.
} 
Exemplo 12a e 12b "Batuque", c. 1-11, c. 17-23

Moderato e muito ritmado

a) (c. 1-11)
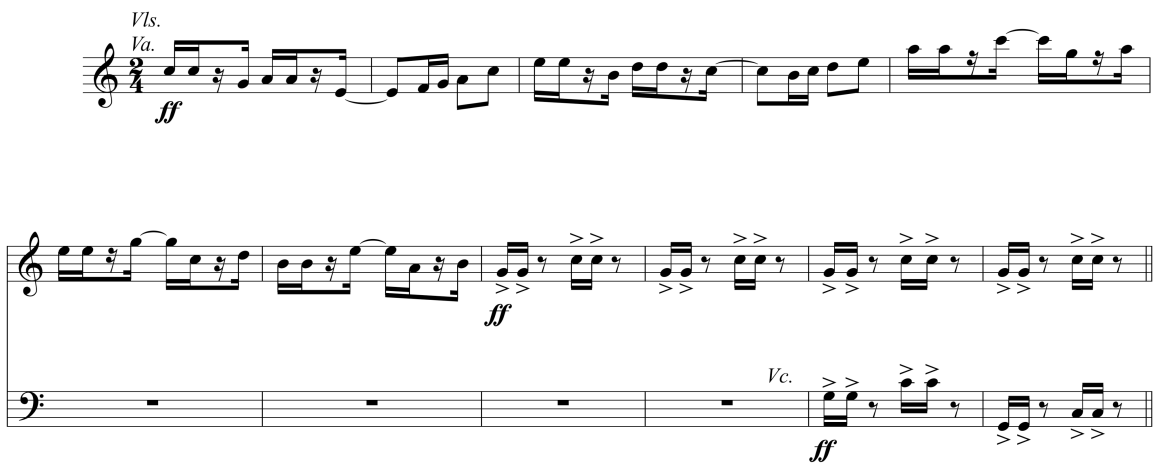

b)

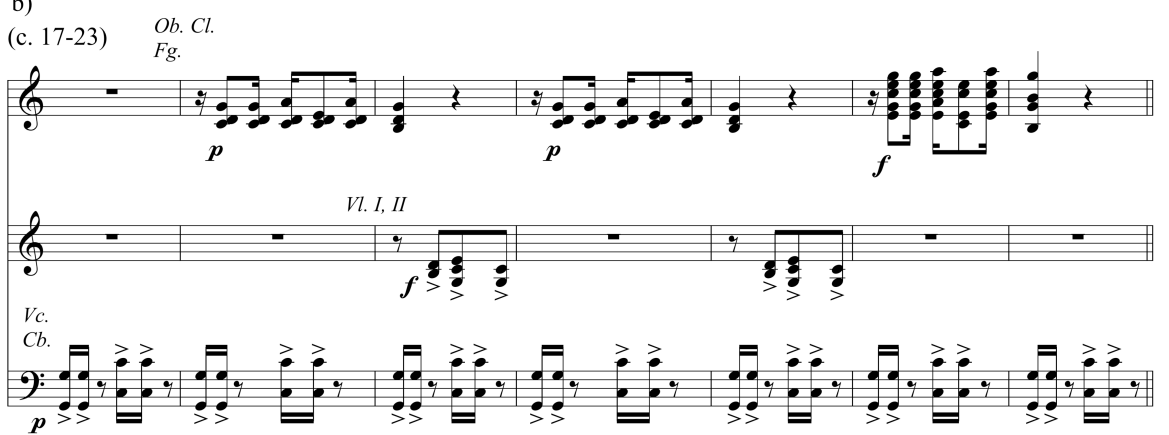

A segunda parte, Doppio Movimento, tem um tema principal que utiliza elementos do tema inicial, mas não apresenta uma relação de derivação. 0 Exemplo 13 ilustra o segundo tema.

Exemplo 13 “Batuque”, segundo tema, c. 77-96

(c. 77-96)
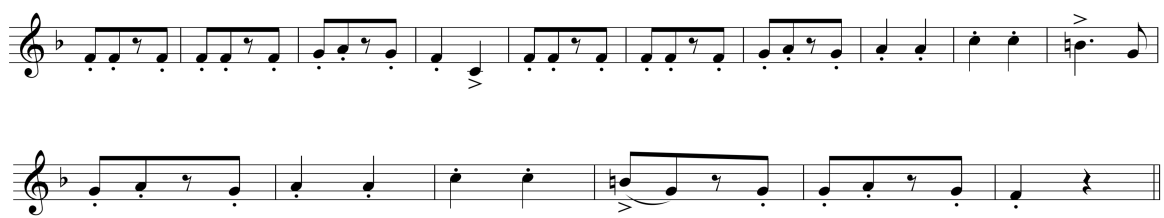

A seção apresenta uma alternância constante entre as regiões de Fá maior e Lá bemol maior. Mas a intenção do compositor de criar um movimento 
contínuo, correspondente à descrição de acelerando da dança, torna-se mais clara ao indicar accel. poco a poco (c. 214), cresc. e string. (c. 240), até a indicação final de Furioso (c. 252)

\section{Conclusão}

A Série Brasileira de Nepomuceno é frequentemente classificada como uma das obras precursoras do nacionalismo na música brasileira. No entanto, outras vertentes de entendimento da obra podem ser consideradas. A do presente texto, ilustra como Realismo em música pode auxiliar no entendimento de uma narrativa musical que pode explicar a própria narrativa da obra em questão. Se pode observar como Nepomuceno pode ter se utilizado de elementos realistas em todos os movimentos da obra, cada qual com seu foco distinto - natureza, urbanidade, aspectos sociais e políticos - até mesmo a ponto de sugerir uma obra de caráter nacionalista, tantas são as referências a aspectos musicais que buscam ilustrar a identidade de uma nação. Estes aspectos nacionais ocorrem como alusões a situações descritivas da natureza, e sócio/políticas, e não como nacionalistas no sentido de apropriação e incorporação de material folclórico na música. A diferença entre estas ideias é reconhecidamente tênue, e a utilização de Realismo em música pode também ocasionar um sentimento de nacionalismo, por evocar ambientações e ideias que fazem parte da realidade de uma determinada nação, e este é o caso da Série Brasileira. Ilustrativo desta conclusão é a própria narrativa que a obra proporciona:

\section{Alvorada na Serra}

Natureza criativa, Imitação da natureza, Deslocamento temporal, Tonmalerei. Elementos estruturais importantes:

Seção A: pedal estático, descrição do amanhecer na montanha

Seção B: elaboração, canto do sabiá

Seção $A^{\prime}$ : reexposição abreviada 


\section{Intermédio}

O Urbano, Dança urbana, Maxixe, forma culta de apresentação: forma sonata. O popular e social brasileiro apresentado de maneira culta.

Elementos estruturais importantes:

Forma Sonata

Exposição: $1^{\circ}$ tema, trans., $2^{\circ}$ tema (maxixe)

Desenvolvimento, retransição $(\mathrm{V} / \mathrm{V}=>\mathrm{I})$

Recapitulação: $1^{\circ}$ tema, trans., $2^{\circ}$ tema (maxixe)

Coda: vivo

\section{Sesta na Rede}

Imitação de costume social, Representação do balanço da rede, Modalismo típico da música nordestina ( $7^{\circ}$ grau abaixado), Natureza e urbano

Elementos estruturais importantes:

Seção A: pedal estático, harmonia estática, monotonia, descritivo

Seção B: fragmentação, cadência, contraste e elaboração

Seção A': reexposição resumida, harmonia estática, monotonia, descritivo

\section{Batuque}

O Negro: Urbano político, Social, Mimese de percussão africana com a intenção de criar êxtase (clímax); Representação da música dos escravos e sua inserção na realidade da República.

elementos estruturais importantes:

movimento rítmico contínuo até atingir um clímax.

Seção A: movimento rítmico contínuo e sincopado, Dó maior, Mi menor/maior, Dó maior, Fá maior

Seção B: diminuição rítmica; alternância entre Fá maior/Lá bemol 


\section{Referências}

ANDRADE, Mário de. Dicionário Musical Brasileiro. (Coord.) Oneyda Alvarenga e Flávia C. Toni. São Paulo: EDUSP, 1989. . Ensaio sobre a música brasileira. São Paulo: Martins Fontes/INL, 1972.

AZEVEDO, Luiz Heitor Corrêa de. 150 Anos de Música no Brasil (1800-1950). Rio de Janeiro: José Olympio Editora, 1956.

BOSI, Alfredo. História Concisa da Literatura Brasileira. São Paulo: Cultrix, 2006.

CARVALHO, Flávio. O Nacional em música na obra de Alberto Nepomuceno: pilares cambiantes nas críticas de jornais cariocas. Rotunda, n. 2, p. 5-14, 2003.

CAZDEN, Norman. Towards a theory of realism in music. Journal of aestheics and art criticism, 10, p. 135-151, 1951.

. Realism in Abstract Music. Music \& Letters, v. 36, n. 1, p. 17-38, Jan. 1955.

CORRÊA, Sergio Alvim. Alberto Nepomuceno-Catálogo Geral. Rio de Janeiro: MEC/Funarte, 1996.

COUTINHO, Afrânio (Org.). A Literatura no Brasil. v. III Realismo-NaturalismoParnasianismo. Rio de Janeiro: Editorial Sul Americana S. A., 1969.

DAHLHAUS, Carl. Realism in Nineteenth-Centuy Music. Cambridge: Cambridge University Press, 1985.

. Foundations of music history. Cambridge: Cambridge University Press, 1983.

Die Musik in Geschichte und Gegenwart. Allgemeine Enzyklopädie der

MusikSachteil und Personenteil in 29 Bänden (MGG). Kassel: Bärenreiter, 2008.

FRISCH, Walter. German Modernism: Music and the Arts. Berkeley: University of California Press, 2005.

GARRATT, James. Inventing Realism: Dahlhaus, Geck, and the unities of discourse. Music and Letters, v. 84, n. 3, p. 456-468, 2003.

GECK, Martin. Zwischen Romantik und Restauration. Musik im Realismus-Diskurs 1848-1871. Stuttgart: Metzler / Kassel, Bärenreiter 2001.

GOSSETT, Philip. Carl Dahlhaus and the "Ideal Type”. 19th-Century Music, v. 13, n. 1, p. 49-56, Summer 1989.

HATCH, Christopher. Reviewed Work(s): Realism in Nineteenth-Century Music by Carl Dahlhaus; Mary Whittall, 19th-Century Music, v. 10, n. 2, p. 187-190, Autumn 1986.

Kobbè-O Livro Completo da Ópera. Conde de Harewood (Ed.). Rio de Janeiro: Jorge Zahar, 1991.

MAGALDI, Cristina. Music in Imperial Rio de Janeiro, European Culture in a Tropical Milieu. Lanham: Maryland, Scarecrow Press, Inc., 2004.

PEREIRA, Avelino R. Música, Scoiedade e Política-Alberto Nepomuceno e a República Musical. Rio de Janeiro: Editora da UFRJ, 2007. 
SQUEFF, Enio e WISNIK, José Miguel. O Nacional e o Popular na Cultura Brasileira-Música. São Paulo: Brasiliense, 2001.

The New Grove Dictionary of Music and Musicians. Stanley Sadie/John Tyrrell (Eds.). London: MacMillan Press LTD., 2001.

VERMES, Monica. Por uma renovação do ambiente musical brasileiro: o relatório de Leopoldo Miguez sobre os conservatórios europeus. Revista Eletrônica de Musicologia, v. VIII, 2004. <http://www.rem.ufpr.br/_REM/REMv8/miguez. html>

E-mail: nortondudeque@gmail.com

Artigo recebido e aprovado em 4 de setembro de 2010 